\title{
Mathematical Modeling of Material Erosion During the Electrical Discharge
}

\author{
Zbigniew Gulbinowicz', Olgierd Goroch ${ }^{1 *}$, Paweł Skoczylas ${ }^{1}$ \\ 1 Institute of Mechanics and Printing, Faculty of Production Engineering, Warsaw University of Technology, \\ ul. Narbutta 85, 02-524 Warszawa, Poland \\ * Corresponding author's e-mail: o.goroch@wip.pw.edu.pl
}

\begin{abstract}
The main factors in Electro Discharge Machining (EDM) are the material removal rate and the relative electrodetool wear. The material removal rate and the relative electrode-tool wear depend on many parameters, in particular on the parameter of electrical discharge and the properties of electrode materials. The developed mathematical model describes the relationship between the parameters of material removal from electrodes and machining parameters. In order to estimate the volume of material removed from electrode, a mathematical model of erosion for single electrical discharge was applied. Estimation of material removal was determined using energy balance. The experimental results confirm the validity of the developed mathematical model.
\end{abstract}

Keywords: rotary electrical discharge machining, rotary electrochemical arc/discharge machining

\section{INTRODUCTION}

In the manufacturing process, difficult-to-cut materials are machined with non-conventional machining methods such as electrochemical [12], waterjet [6], hybrid $[7,13]$ and electro discharge machining $[1,15]$. These materials are also resistant to the electrical erosion process.

The conducted research on the electrical discharge machining of difficult-to-cut materials mostly focuses on the investigation of the physical phenomenon of the process $[3,4,11]$, improving of surface layers properties $[7,14]$ and optimization of process technology [2]. The different physicochemical properties of the difficult-to-cut materials, in comparison with the easy-to-cut materials are a reason of different conditions during electrical erosion [10]. It requires changing the parameters of machining in relation to the parameters specified in the technical documentation of the EDM machine tool.

Therefore, it is important to experimentally determine the influence of the electrodischarge processing parameters on the properties of the workpiece. For this reason, the experimental studies on the impact of EDM process parameters (discharge current and pulse time) on electroerosion were carried out.

\section{Mathematical model of electroerosion}

In the electrical discharge machining, the material from the machined surface is removed by electrical discharges in the dielectric filling the inter-electrode gap. When the electrodes are close to few micrometers, the electric field strength can reach the limit value $E_{g}$ in some places, and dielectric layer breaks down and electrical discharge occurs. During electrical discharge, the surfaces of electrodes located under the plasma channel are exposed to high temperature and pressure generated in the plasma channel and gas bladder. The effect of the surface heat source and heat source, which is released inside the electrodes under the influence of the current flow (i.e. Joule heat), causes the heating up of the material to the melting temperature and then to the boiling point. The quantities of heat delivered to 
the anode and cathode are most often different $[5,8,17]$. The estimates made in [18] showed that the influence of Joule heat is negligible and can be omitted in calculations. For these reasons, the intensity of erosion in a single discharge mainly depends on the energy delivered to the electrode surfaces.

The total energy of the discharge $\mathrm{E}_{\mathrm{c}}$ has three components: energy supplied to the surface of the anode $E_{a}$, energy supplied to the surface of the cathode $\mathrm{E}_{\mathrm{k}}$, energy lost in the inter-electrode gap $E_{1}$ (Figure 1a). Only the part of the total energy that is transmitted to the electrode is involved in the electroerosion of an electrode. In turn, the energy supplied to the electrodes $\left(\mathrm{E}_{\mathrm{a}}, \mathrm{E}_{\mathrm{k}}\right)$ can be used on (Figure $1 \mathrm{~b}$ ):

- melting and evaporating the electrode material,

- thermal radiation and heat transfer through a dielectric at the electrode-liquid material boundary,

- heating the material with thermal conductivity.

The heat transferred to the electrode causes an increase of the material temperature, initially to the melting temperature $T_{m}$, and then to the boiling point $T_{b}$. As a result of melting and then evaporating the material, approximately spherical craters are formed in the material. The total volume of the removed material is equal to the sum of the volumes of the craters created in electrical discharges.

The volume of a single crater depends on the amount of heat absorbed by the electrode material and its thermal properties. An estimation of the

a)

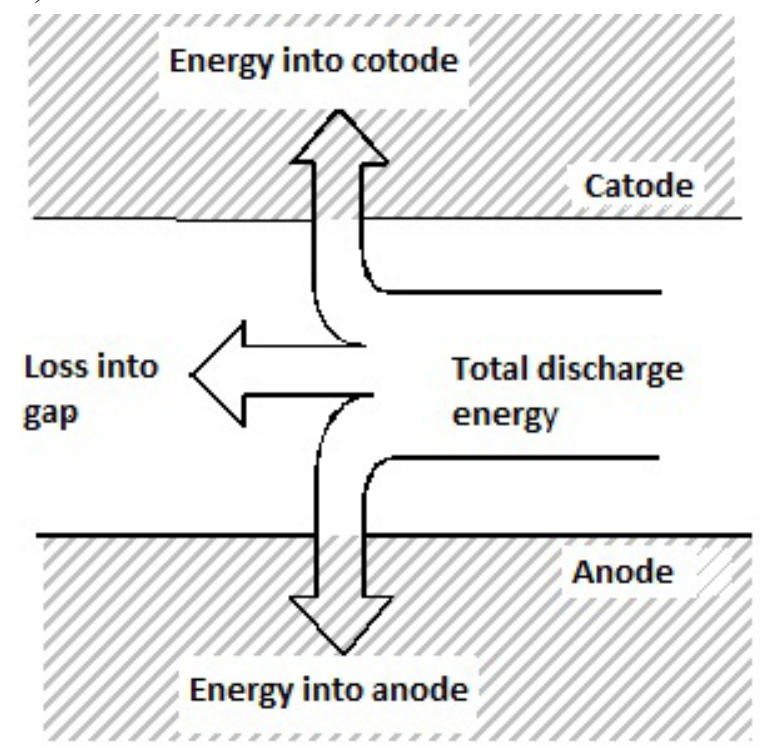

volume of the crater for a single discharge can be made using the energy balance.

The effective energy supplied to the surface of the electrodes causes melting, evaporation of the material and heating of the material around the crater. Part of the molten material can be removed from the crater as a result of implosion, boiling or electrodynamic forces, whereas the remainder stays in the crater and solidifies.

$$
\mathrm{E}_{\mathrm{ef}}=\mathrm{E}_{\mathrm{m}}+\mathrm{E}_{\mathrm{r}}+\mathrm{E}_{\mathrm{v}}
$$

where: $E_{m}$-energy used to melt material removed from the crater

$E_{r}$ - the energy used to melt the material left in the crater

$E_{V}$ - energy used for evaporation of the material

However, the evaporated material is removed from the crater completely. The volume of the crater will therefore depend on what part of the material will be evaporated and how much molten material will be removed from the crater.

The energy required to melt the material removed from the crater is determined from the equation:

$$
E_{m}=\Delta V_{L} \cdot \rho_{s} \cdot\left[L_{m}+C_{s}\left(T_{m}-T_{0}\right)\right]
$$

where: $\Delta V_{L}-$ volume of molten and removed material

$\rho_{s}$ - material density

$T_{m}-$ melting temperature

$T_{0}$ - initial temperature

$C_{s}$ - specific heat of the solid material

$L_{m}-$ heat of melting

b)

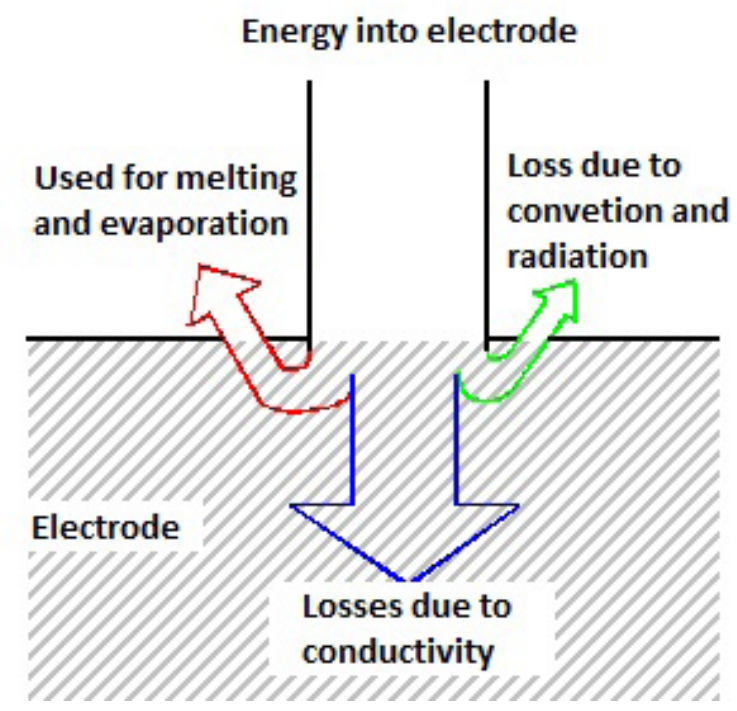

Fig. 1. Distribution of discharge energy 
In the same way, the energy required for melting the material, which is left in the crater, is determined:

$$
E_{m}=\Delta V_{r} \cdot \rho_{s} \cdot\left[L_{m}+C_{s}\left(T_{m}-T_{0}\right)\right]
$$

where: $\Delta V_{r}-$ volume of molten material left in the crater

The heat associated with evaporation of the material has the largest share in total energy. The energy needed to evaporate material is:

$E_{v}=\rho \cdot \Delta V_{V} \cdot\left[r_{v}+C_{L}\left(T_{b}-T_{m}\right)+C_{S}\left(T_{m-} T_{0}\right)+L\right]$

where: $\Delta V_{V}$ - volume of evaporated material

$T_{b}$ - boiling point

$C_{L}$ - specific heat of the material in the liquid state

$r_{V}$ - heat of evaporation

Taking into account the losses $\mathrm{E}_{\mathrm{ef}}$ due to heating of material by conduction Q, the energy balance takes the form:

$$
\begin{aligned}
& \left.E_{e f}=\rho \cdot \Delta V_{V} \cdot \mid r_{v}+C_{L}\left(T_{b}^{\prime}-T_{m}\right)+C_{S}\left(T_{m-T_{0}}\right)+L\right]+ \\
& +\rho \cdot \Delta V_{L}\left[L+C_{S}\left(T_{m}-T_{0}\right)\right]+\rho \cdot \Delta V_{r} \cdot\left[L+C_{S}\left(T_{m}-T_{0}\right)\right]+Q
\end{aligned}
$$

In the approximate analysis, it was assumed that $C_{s}=C_{L}=C$ and the following equation was introduced:

$$
\frac{\Delta V_{V}}{\Delta V}=\alpha, \frac{\Delta V_{L}}{\Delta V}=\beta \text { and } \frac{\Delta V r}{\Delta V}=\gamma \text { wherein } \alpha+\beta+\gamma=1
$$

From the balance (5), after the introduction of the determinations above, the volume of the crater is expressed by the equation (6):

$$
\Delta V=\frac{E_{e f}-Q}{\rho \cdot\left[\alpha \cdot r_{v}+L+\alpha \cdot C\left(T_{b}-T_{0}\right)+(1-\alpha) C\left(T_{m}-T_{0}\right)\right]}
$$

The maximum value $\Delta V_{\max }$ is when $\alpha=0$ and $\gamma=0$, when erosion occurs only due to material melting, which is then completely removed $(\beta=0)$.

$$
\Delta V_{\max }=\frac{E_{e f}-Q}{\rho \cdot\left[L+C\left(T_{m}-T_{0}\right)\right]}
$$

The minimum value $\Delta V_{\min }$ is when $\alpha=1$, so when the material is removed only as a result of evaporation.

$$
\Delta V_{\min }=\frac{E_{e f}-Q}{\rho \cdot\left[r_{v}+L+C\left(T_{b}-T_{0}\right)\right]}
$$

The actual volume of the crater is dependent on the ratio of the amount of material removed by evaporation to the material removed by melting and is within the range of $\mathrm{V}_{\mathrm{v}} \leq \mathrm{V}_{\text {rzecz }} \leq \mathrm{V}_{\mathrm{m}}$. The contribution of erosion to evaporation is much greater than that of erosion due to material melting. This ratio depends on the power generated in pulse and on discharge time. In EDM machining, the evaporation part is lower at the pulse times above $100 \mu \mathrm{s}$, and it increases and becomes decisive with a reduction of pulse time below $100 \mu \mathrm{s}[9,16,19]$.

\section{Experimental verification}

Two materials, significantly different in their parameters, were prepared for the research, in order to show why EDM is applied to the machining of difficult-to-work materials. The first material is popular structural steel $\mathrm{C} 45$, the second material is tungsten heavy alloys (WSC).

Tungsten heavy alloys, due to the very high melting point, are produced by sintering powders with a liquid phase. In the result, a two-phase material with a microstructure made of spherical tungsten grains, uniformly distributed in a relatively soft matrix of nickel alloy, is obtained. Due to this specific microstructure, these alloys are often called tungsten composites.

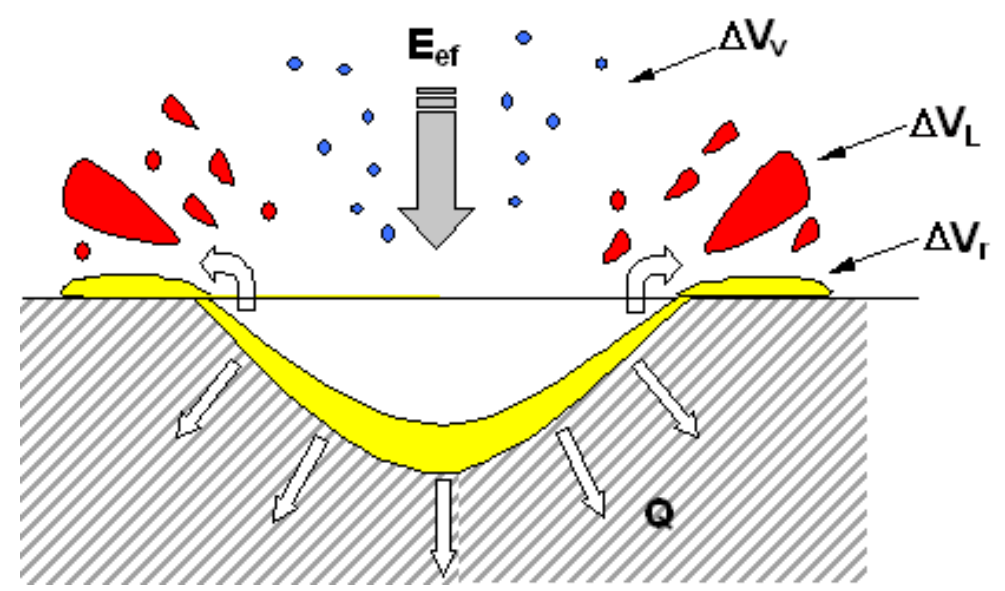

Fig. 2. Diagram of the erosion of the crater 
The material for the working electrode must be highly resistant to the electric erosion and it should also have high electrical and thermal conductivity as well as a high melting point. The following materials are often used: brass, graphite, cast iron, electrolytic copper and tin alloys. A copper electrode was used in the research.

The research was carried out on a test stand equipped with a transistor generator. The generator generated single voltage pulses of a rectangular shape and a value of $160 \mathrm{~V}$. The set parameters of the pulse and current time are given in the table.

Process parameters were monitored using the NI PXI-PCI 5112 DAQ.

On the basis of the collected data, the actual energy in the gap for a single pulse was calculated from the formula (9):

$$
E_{c}=\int_{0}^{t_{i}} u \cdot i \cdot d t
$$

where: $u$-discharge voltage

$i$ - discharge current

$t_{i}$ - discharge time

After testing on an MOTIC optical microscope, the diameters of individual craters were measured and the actual volume was calculated from the formula (10):

$$
V_{\text {real }}=\frac{(\pi * D * h)}{8}+\frac{\left(\pi * h^{3}\right)}{6}
$$

where: $D$ - diameter of crater,

$$
h-\text { depth. }
$$

The results of measurements and crater volume calculations are presented in Table 2 .

Table 1. The pulse parameters

\begin{tabular}{|c|c|c|}
\hline Sample & $\mathrm{t}_{\mathrm{i}}[\mu \mathrm{s}]$ & $\mathrm{I}] \mathrm{A}]$ \\
\hline 1 & 100 & 8 \\
\hline 2 & 100 & 2 \\
\hline 3 & 200 & 8 \\
\hline 4 & 200 & 2 \\
\hline
\end{tabular}

These are the average values for several single discharges.

It can be seen that the volume of crater grows for both a higher current and a longer pulse. It can be also seen that the volume for steel is larger than for WSC.

Then the results of the experiment were compared with the results of mathematical modeling of erosion. The theoretical calculations were based on the assumption that the percentage of energy used for material removal is within range of $\mathrm{Ca}=0.4-2 \%$ for the anode. The minimum volume was calculated from formula 8 , and the maximum volume from formula 7 . The material data given in the table 3 were used for calculations. Figures 3 to 6 show the results of calculations and measurements of the volume of crater for $\mathrm{C} 45$ steel.

The energy for sample 1 was $0.096 \mathrm{~J}$. The calculated volumes for melting are in the range $5 \cdot 10^{-14}-2.5 \cdot 10^{-13} \mathrm{~m}^{3}$, while for evaporation in the range $3.3 \cdot 10^{-14}-6.7 \cdot 10^{-15} \mathrm{~m}^{3}$. The experimental value is between these values. Figure 4 shows the results of calculations and measurements for sample 2. The energy of the discharge was $0.024 \mathrm{~J}$. The volumes for melting are in the range of $1.3 \cdot 10^{-14}-6.3 \cdot 10^{-14} \mathrm{~m}^{3}$, while for evaporation in the range of $1.7 \cdot 10^{-15}-8.3 \cdot 10^{-15} \mathrm{~m}^{3}$. The experimental value of crater volume is slightly above the average value obtained from the calculation. The discharge energy for sample 3 was $0.192 \mathrm{~J}$. The volumes for melting are in the range $1 \cdot 10^{-13}$ $-5 \cdot 10^{-13} \mathrm{~m}^{3}$, while for evaporation in the range of $1.3 \cdot 10^{-14}-6.7 \cdot 10^{-14} \mathrm{~m}^{3}$. The experimental value is at the level of minimum values (for evaporation) obtained from the calculations. For sample 4, the discharge energy was $0.48 \mathrm{~J}$. The volume values for melting are in the range of $2.5 \cdot 10^{-14}-1.3 \cdot 10^{-13}$ $\mathrm{m}^{3}$, while for evaporation in the range of $3.3 \cdot 10^{-15}$ $-1.7 \cdot 10^{-14} \mathrm{~m}^{3}$. It can be seen that the experimental value is between these values.

Figures 7 to 10 present the results of calculations and measurements of crater volume for WSC. For sample 1, the discharge energy was

Table 2. Results of crater volume measurement

\begin{tabular}{|c|c|c|c|c|c|c|}
\hline \multirow{2}{*}{$\begin{array}{c}\text { Material } \\
\text { sample }\end{array}$} & \multicolumn{3}{|c|}{$\mathrm{C} 45$} & \multicolumn{2}{c|}{ WSC } \\
\hline & $\mathrm{D}[\mathrm{m}]$ & $\mathrm{h}[\mathrm{m}]$ & $\mathrm{V}_{\text {real }}\left[\mathrm{m}^{3}\right]$ & $\mathrm{D}[\mathrm{m}]$ & $\mathrm{h}[\mathrm{m}]$ & $\mathrm{V}_{\text {real }}\left[\mathrm{m}^{3}\right]$ \\
\hline 1 & 0.0001 & 0.0000125 & $3.68 \cdot 10^{-14}$ & 0.00006 & 0.0000075 & $1.08 \cdot 10^{-14}$ \\
\hline 2 & 0.00007 & 0.00000875 & $3.61 \cdot 10^{-14}$ & 0.00004 & 0.000005 & $3.21 \cdot 10^{-15}$ \\
\hline 3 & 0.00015 & 0.00001875 & $3.92 \cdot 10^{-14}$ & 0.0001 & 0.0000125 & $5.01 \cdot 10^{-14}$ \\
\hline 4 & 0.00012 & 0.000015 & $3.75 \cdot 10^{-14}$ & 0.00005 & 0.00000625 & $6.26 \cdot 10^{-15}$ \\
\hline
\end{tabular}


Table 3 Material properties used for calculations.

\begin{tabular}{|c|c|c|c|c|c|c|}
\hline Material & $\begin{array}{c}\text { Heat of evaporation } \\
\mathrm{r}_{\mathrm{v}}[\mathrm{J} / \mathrm{kg}]\end{array}$ & $\begin{array}{c}\text { Specific heat } \\
{\left[\mathrm{J} / \mathrm{kg}^{\circ} \mathrm{C}\right]}\end{array}$ & $\begin{array}{c}\text { Heat of melting } \\
{[\mathrm{J} / \mathrm{kg}]}\end{array}$ & $\begin{array}{c}\text { Melting point } \\
{\left[{ }^{\circ} \mathrm{C}\right]}\end{array}$ & $\begin{array}{c}\text { Boiling point } \\
{\left[{ }^{\circ} \mathrm{C}\right]}\end{array}$ & Density $\left[\mathrm{kg} / \mathrm{m}^{3}\right]$ \\
\hline C45 & 6339000 & 452 & 278000 & 1535 & 3050 & 7875 \\
\hline WSC & 4350000 & 199 & 191000 & 3340 & 5900 & 17450 \\
\hline
\end{tabular}

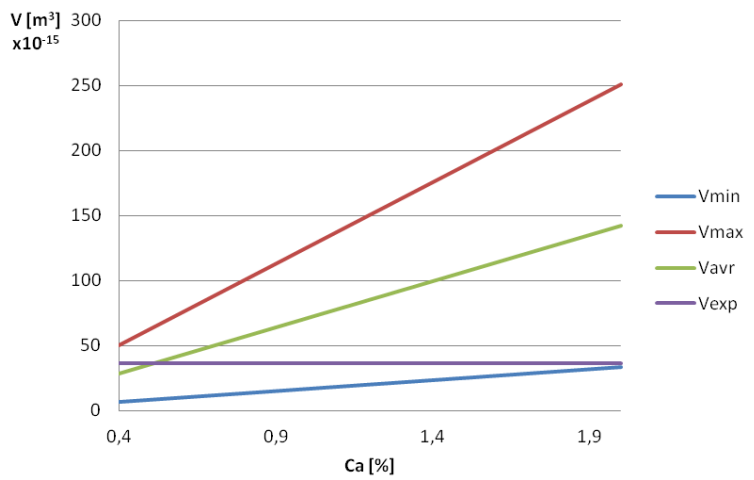

Fig. 3. Comparison of experimental and computer simulations results for sample 1 (C45 steel)

$0.072 \mathrm{~J}$. The volumes for melting are in the range of $1.9 \cdot 10^{-14}-9.6 \cdot 10^{-14} \mathrm{~m}^{3}$, while for the evaporation in the range of $3.2 \cdot 10^{-15}-1.6 \cdot 10^{-14} \mathrm{~m}^{3}$. The experimental value is at the level of the minimum values obtained from the calculations. The discharge energy for the sample 2 was $0.025 \mathrm{~J}$. The volume values for the melting are in the range $6,7 \cdot 10^{-15}-3,3 \cdot 10^{-14} \mathrm{~m}^{3}$, while for the evaporation in the range $1,1 \cdot 10^{-15}-5,5 \cdot 10^{-15} \mathrm{~m}^{3}$. As before, experimental value is at the minimum level (for evaporation).

For sample 3, the discharge energy was $0.237 \mathrm{~J}$. The volume values for melting are in the range of $6.3 \cdot 10^{-14}-3.2 \cdot 10^{-13} \mathrm{~m}^{3}$, while for the evaporation in the range of $1 \cdot 10^{-14}-5,2 \cdot 10^{-14} \mathrm{~m}^{3}$. It can be noticed that the experimental value is between these values. For sample 4, the energy

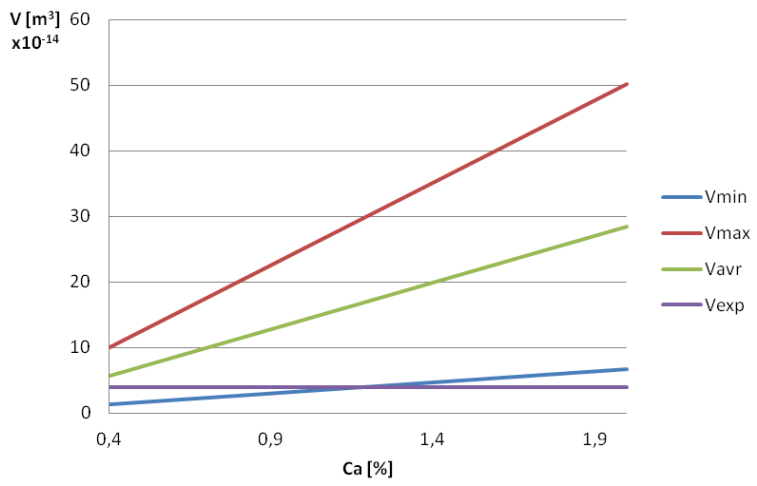

Fig. 5. Comparison of experimental and computer simulations results for sample 3 (C45 steel)

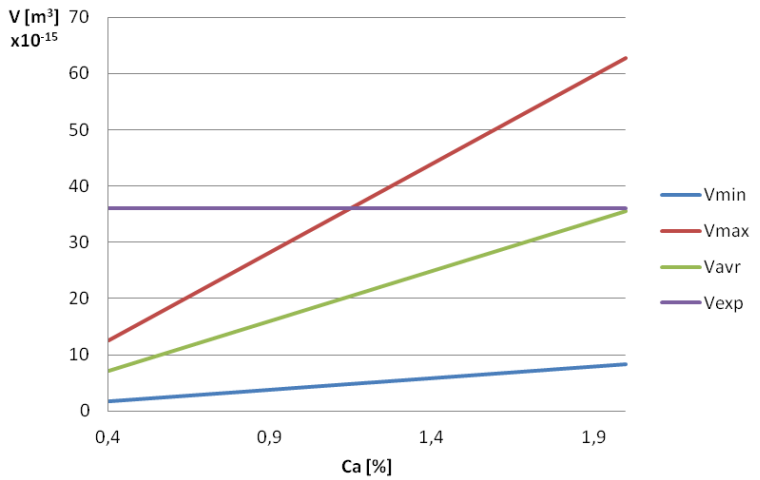

Fig. 4. Comparison of experimental and computer simulations results for sample 2 (C45 steel)

was $0.046 \mathrm{~J}$. The volume values for melting are in the range of $1.2 \cdot 10^{-14}-6.2 \cdot 10^{-14} \mathrm{~m}^{3}$, while for the evaporation in the range of $2 \cdot 10^{-15}-1 \cdot 10^{-14}$ $\mathrm{m}^{3}$. The experimental value is at the level of the minimum values obtained during the calculation. While analyzing the graphs presenting the comparative characteristics of volume as a function of the $\mathrm{C}_{\mathrm{a}}$ factor, it can be seen that for steel in samples $1,2,4$, the experimental volume is located between the minimum volume and the maximum volume. In sample 3, the experimental volume of the crater is located at the minimum volume. However, for the WSC in the samples 1,2,4, the experimental volume is located on the level of the minimum volume. In sample 3, the experimental volume is between the minimum and the average values.

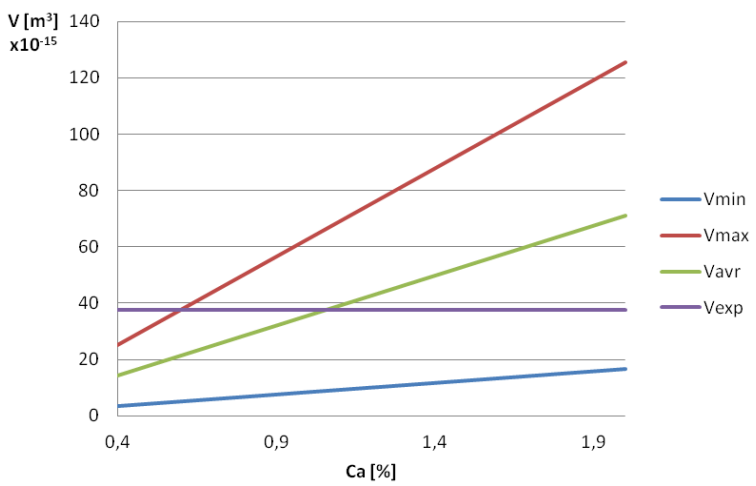

Fig. 6. Comparison of experimental and computer simulations results for sample 4 (C45 steel) 


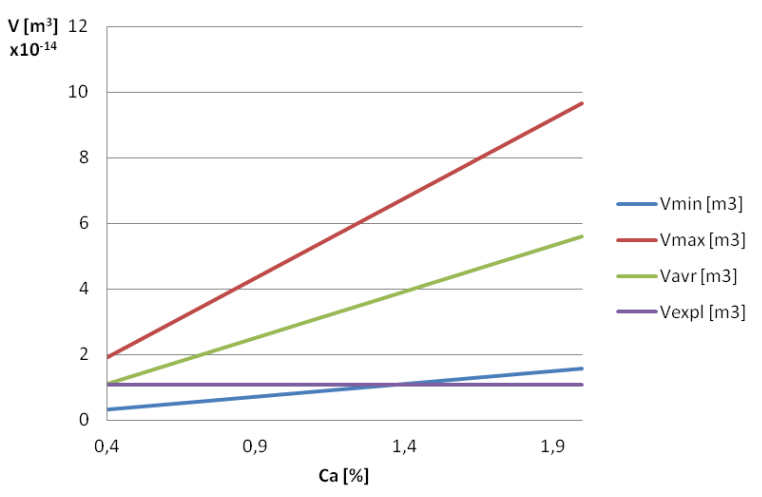

Fig. 7. Comparison of experimental and computer simulations results for sample 1 (WSC)

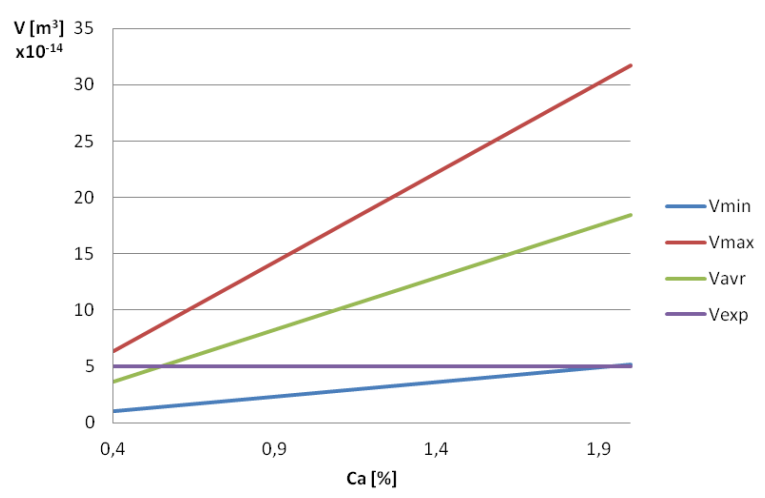

Fig. 9. Comparison of experimental and computer simulations results for sample 3 (WSC)

\section{CONCLUSION}

The conducted mathematical modeling of the electrical discharge erosion process enables us to know the influence of process conditions and material properties on the volume of material removed from the electrode. Only a small percentage of energy is used to remove material from the electrode. The current density and pulse time have the greatest influence on the volume of the craters.

A lower ratio of energy utilization for a longer pulse on steel may result from a larger volume of melted metal remaining on the electrode. During the tests it was found that WSC is a difficult to process material, and the percentage of energy used for material removal is smaller than for steel. It may also be associated with a larger volume of molten metal left on the electrode. For this purpose, it required to measure both the volume of the crater and the material left on the electrode on a metallographic sample.

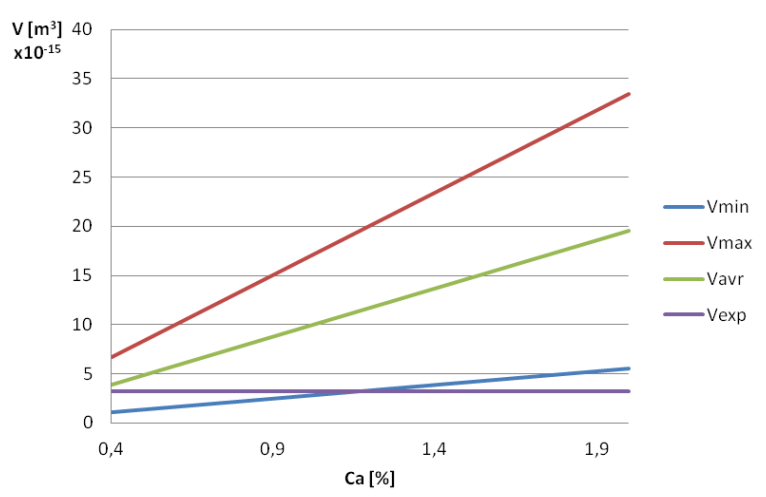

Fig. 8. Comparison of experimental and computer simulations results for sample 2 (WSC)

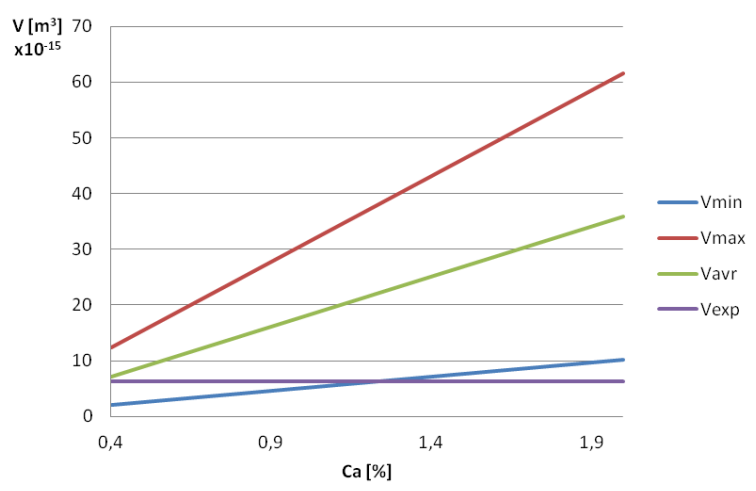

Fig. 10. Comparison of experimental and computer simulations results for sample 4 (WSC)

\section{REFERENCES}

1. Abidi M.H., Al-Ahmari A.M., Siddiquee A.N., Mian S.H., Mohammed M.K., Rasheed M.S., Metals, 7 486, 2017.

2. Aharwal K.R., Sitaram, Krishna C.M., Materials Today: Proceedings 5, 2018, 5391-5397.

3. Bains P.S., Sidhu S.S., Payal H.S., Materials and Manufacturing Processes 31, 2016, 553-573.

4. Chen R., Guo Z.N., Liu J.W., Yue T.M., S.W., Materials Research Innovations 19, 2015, 392-396.

5. Hayakawa S., Yuzawa M., Kunieda M., Nishiwaki N.: Time Variation and Mechanism of Determining Power Distribution in Electrodes during EDM Process, IJEM, 6, 2001, 19-26.

6. Hlaváč L.M., Krajcarz D., Hlaváčová I.M., Spadło S., Precision Engineering 50, 2017, 148-159()

7. Hourmand, Farahany M.S., Sarhan A.A.D., Noordin M.Y., Int J Adv Manuf Technol 77, 2015, 831-838.

8. König W., Wertheim R., Zwirin Y., Toren M.: Material removal and energy distribution in electri- 
cal discharge machining. Annals of the CIRP Vol. 24/1/75, 95-100.

9. Kunieda M., Lauwers B., Rajurkar K.P., Schumacher B.M.: Advancing EDM through Fundamental Insight into the Process, CIRP

10. Nicholls C.J., Boswell B., Davies I.J., Islam M.N., Int J Adv Manuf Technol 90, 2017, 2429-2441.

11. Rozenek M., Kozak J., Dąbrowski L., Łubkowski K., Journal of Materials Processing Technology 109, 2001, 367-370.

12. Ruszaj A., Gawlik J., Skoczypiec S., Management and Production Engineering Review 7, 2016, 34-41.

13. Ruszaj A., Skoczypiec S., Wyszyński D., Management and Production Engineering Review 8, 2017, 81-90.
14. Singh Sidhu S., Singh Bains P., Materials Today: Proceedings 4, 2017, 3243-3251.

15. Świercz R., Oniszczuk-Świercz D., Metals, 7, 2017, 550 .

16. Van Dijck F.: Physico-Mathematical Analysis of the Electro Discharge Machining Process, Dissertation of Katholieke Universiteit Leuven.

17. Xia H., Kunieda M., Nishiwaki N.: Removal Amount Difference between Anode and Cathode in EDM Process, IJEM, 1, 1996, 45-52.

18. Zingerman A.S.: Regarding the problem of the volume of molten metal during electrical erosion. Soviet Phisics-Solid 1, 1959, 255-260.

19. Zolotych B.N.: The Mechanism of Electrical Erosion of Metals in Liquid Dielectric Media, Soviet Physics-Technical Physics, 4, 12, 1959, 1370-1373. 